\title{
Rational engineering of a carboxylesterase for the synthesis of
}

\section{polyesters for biomedical applications}

\author{
Beatriz C. Almeida, ${ }^{1,5}$ Pedro R. Figueiredo, ${ }^{1,5}$ Daniel F.A.R. Dourado, ${ }^{2}$ Stephanie Paul, ${ }^{2}$ Derek J. Quinn, ${ }^{2}$ \\ Thomas S. Moody, ${ }^{2,3}$ Andreia F. Sousa, ${ }^{4}$ Armando J. D. Silvestre, ${ }^{4}$ Alexandra T. P. Carvalho ${ }^{1 *}$ \\ ${ }^{1} \mathrm{CNC}$ - Center for Neuroscience and Cell Biology, Institute for Interdisciplinary Research (IIIUC), \\ University of Coimbra, 3004-504 Coimbra, Portugal. ${ }^{2}$ Almac Sciences, Department of Biocatalysis and \\ Isotope Chemistry, Almac House, 20 Seagoe Industrial Estate, Craigavon, BT63 5QD, Northern Ireland, \\ UK. ${ }^{3}$ Arran Chemical Company, Unit 1 Monksland Industrial Estate, Athlone, Co. Roscommon, Ireland. \\ ${ }^{4}$ CICECO - Aveiro Institute of Materials and Department of Chemistry,3810-193 Aveiro, Portugal. \\ ${ }^{5}$ These authors contributed equally.
}

\begin{abstract}
Enzymatic synthesis of polymeric biobased materials is a powerful approach to make these processes greener, more economical, and safer for scale-up. Herein, we have reengineered a hyperthermophilic carboxylesterase to improve product yield in the synthesis of poly( $\varepsilon$-caprolactone) and triblock poly( $\varepsilon$-caprolactone)-co-poly(ethylene glycol), two important biomaterials. Our design strategy comprised extensive Quantum Mechanics/Molecular Mechanics Molecular Dynamics simulations, enzyme expression, enzymatic assays and characterization of the products. Our best mutants showed yields for poly(E-caprolactone) of 30-70\%, while the WT enzyme only achieved 9-12\%. The best mutants consistently formed stronger hydrogen bonds to the nucleophilic oxygen in the reactants and with the leaving lactone oxygen at the intermediate 1 , reflecting the best active site compromise preorganization
\end{abstract}


for stabilization for two consecutive transition states that involve the same active site machinery. Our findings set the underpinning grounds to redesign other enzymes for polyesterification reactions.

biodegradable polyesters, polycaprolactone, polyethylene glycol, enzymatic synthesis, carboxylesterase, AfEST, lipase, CalB, QM/MM MD simulations, protein engineering.

\section{Introduction}

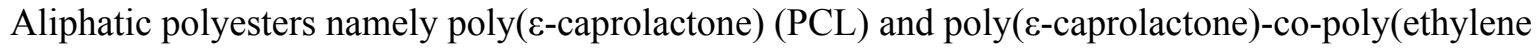
glycol) (PCL-PEG) are bioresorbable materials with attractive properties. They are widely used in various biomedical applications, such as systems for drug and gene delivery or implant materials for tissue engineering. ${ }^{1-3}$ Their synthesis can be accomplished mainly by two polymerization routes: polycondensation polymerization or ring-opening polymerization (ROP). The ROP mechanism has been continuously refined with several combinations of initiators and catalysts evaluated to attain the synthesis of the desired polymer properties. Enzyme-catalyzed ROP (eROP) was considered one of the most promising approaches. ${ }^{4,5}$ Overall, enzymatic synthesis has several advantages over traditional chemical synthesis that make them better suited to obtain products for biomedical applications, namely by: 1) the use of milder/greener reaction conditions in terms of temperature and pressure conditions; 2) the type of solvents involved; 3) the high control of the stereo-, chemo-, regio- and choro-selectivity; 4) the absence of toxic metal and/or organo-catalysts. ${ }^{5,6}$

The wild-type (WT) serine-hydrolases (e.g. esterases and lipases) have been extensively tested for eROP

of lactones or macrocyclic esters. ${ }^{7-15}$ A generalized eROP reaction of $\varepsilon$-caprolactone $(\varepsilon-\mathrm{Cl})$ is shown in Fig. 1. 


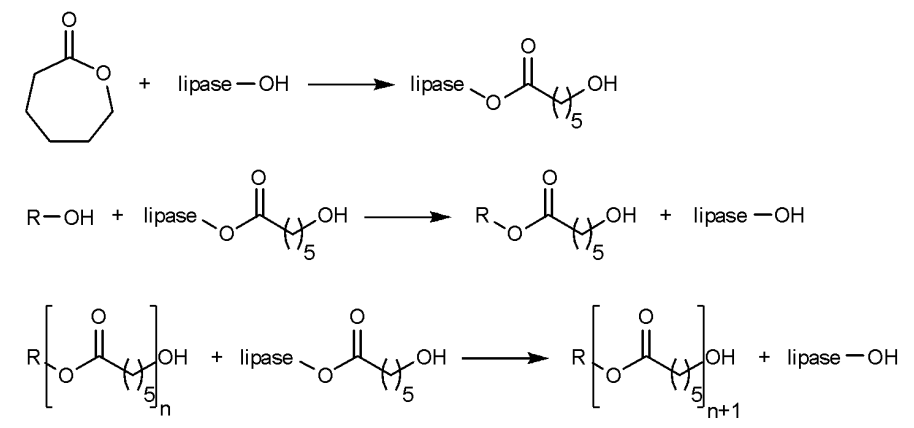

Fig. 1 Generalized eROP reaction for lipase conversion of $\boldsymbol{\varepsilon}-\mathbf{C l}$ into PCL.

The most commonly employed enzyme has been Candida antarctica lipase B (CalB), a mesophilic enzyme usually used in the immobilized form on Lewatit VP OC 1600 (Novozyme 435). ${ }^{16-19}$ CalB immobilization improves its stability and reusability, ${ }^{20,21}$ however, it also has disadvantages, such as lower activity and selectivity for several monomers ${ }^{22}$, mass-transfer issues and the high-cost of these enzymes, particularly at large scale. Furthermore, petroleum-based carriers for enzyme immobilization are not truly green. Nonetheless, one the major limitations of these enzymatic polymerizations is the poor control of the polymers molecular weight, for example, immobilized CalB has been previously shown to produce PCL (number average of molecular weight $\left(\mathrm{M}_{\mathrm{n}}\right)$ of $9,480 \mathrm{~g} / \mathrm{mol}$ in toluene at $60{ }^{\circ} \mathrm{C}$ for $88 \mathrm{hr}$ ), PCL-PEG (63-70 \% yield at $70{ }^{\circ} \mathrm{C}, \mathrm{M}_{\mathrm{n}}$ of $12500-17600^{15}$ and in a latter work, $\mathrm{M}_{\mathrm{n}}$ of 11900-19000 and 1.28-1.59 polydispersity index at $70{ }^{\circ} \mathrm{C}^{14}$ ). This enzyme was also previously reengineered for PCL synthesis, however, the obtained polymers $\mathrm{M}_{\mathrm{n}}$ values (between 5730-12280 $\mathrm{g} / \mathrm{mol}$ ) were still highly variable and similar to those obtained with the WT enzyme. ${ }^{23}$ All of these limitations still prevent these eROP reactions from industrial adoption, thus requiring the use of other enzymes and/or modified enzymes. An alternative approach is to employ enzymes from hyperthermophile hosts. In general, these enzymes have many advantages for industrial applications; notably, they are easier to purify when expressed in mesophilic hosts and have a higher resistance to chemical denaturants. Reactions at higher temperatures also provide fewer risks for microbial contamination. ${ }^{24}$ Finally, higher temperatures also decrease the viscosity of the medium and aggregation of the resulting polymer products, allowing for the enzyme to more easily access the polymer units, which is very promising for large-scale polyesters synthesis. The 
hyperthermophilic carboxylesterase from the archaeon Archaeoglobus fulgidus (AfEST) was previously employed in the synthesis of PCL. ${ }^{25-27}$ The existing forms, free and immobilized, allow the formation of polymeric chains with $M_{n}$ values between $670-1580 \mathrm{~g} / \mathrm{mol}$ and monomer conversion ratios between $45-100 \%$ at $80{ }^{\circ} \mathrm{C} .{ }^{25-27}$ Interestingly, the immobilized form did not substantially improve the polymer $\mathrm{M}_{\mathrm{n}}{ }^{26,27}$ Comparing with CalB, AfEST displayed a better Michaelis-Menten constant $\left(\mathrm{k}_{\mathrm{M}}\right)$ for $\varepsilon$-Cl, but an inferior rate constant $\left(\mathrm{k}_{\mathrm{cat}}\right){ }^{25}$ Both enzymes have an $\alpha / \beta$ hydrolase fold composed by a Ser-His-Asp catalytic triad and an oxyanion hole region responsible for the stabilization of the negative charge developed on the oxygen atom of the tetrahedral intermediate structures. ${ }^{28,29}$ The serine residue of the catalytic triad act as the nucleophile and the histidine as an acid/base (transferring protons between the catalytic serines and the substrate) that are stabilized by the aspartate residue. ${ }^{28,30,31}$ These enzymes differ on the residues that make the oxyanion hole and on the sizes and orientation of the acyl-binding and alcohol-binding pockets. ${ }^{32,33}$ Additionally, AfEST has a cap domain composed of five helices from two separate regions (residues 1-54 and 188-246), ${ }^{33}$ whereas CalB active site is flanked by two highly mobile short $\alpha$-helixes, helix $\alpha 5$ (residues 142-146) and helix $\alpha 10$ (residues 268-287), where the former acts as the putative lid..$^{34,35}$

Protein engineering has been essential to better understand protein's function, enzyme dynamics, and active site architectures. ${ }^{36}$ To the best of our knowledge AfEST has not been engineered for polymerization reactions. It has however been engineered to improve the affinity between AfEST and organophosphorus compounds ${ }^{37}$ and in the resolution of ibuprofen esters. ${ }^{38}$ Here, we have used this enzyme, for the first time, as a starting point for reengineering for enzymatic polymerization reactions. We performed computational design and experimental validation for AfEST mutants to improve PCL and triblock PCL-b-PEG-b-PCL synthesis. We have calculated the one- (1D) and two-dimensional (2D) profiles for the acylation steps for all the variants. The enzyme mutants were then expressed, the reactions tested, and the obtained polymers characterized.

\section{Results}




\section{Enzyme mutant's free energy surfaces for the acylation step}

Enzymatic synthesis is nowadays widely used to obtain fine chemicals and active pharmaceutical ingredients (APIs). However, the use of enzymes for polymer synthesis has been lagging behind these applications. Immobilized enzymes have mainly dominated polyester synthesis, but, although immobilized enzymes are more stable can be reused, these enzymes are expensive to use in large scale, and the use of petroleum-based carriers for enzyme immobilization is not truly green.

Recombinant thermophile enzymes can be used in chemical processing due to their intrinsic in-built properties since their origin host has evolved to live under extreme conditions that are normally denaturing for many mesophilic enzymes. Here we have used the AfEST carboxylesterase as our starting point and as a proof-of-concept, we tried to turn it more similar in terms of polyester synthesis activity to CalB, without compromising its stability. Our rational approach was based on a detailed characterization of the reaction profiles for the rate-limiting acylation step (Fig. 2).

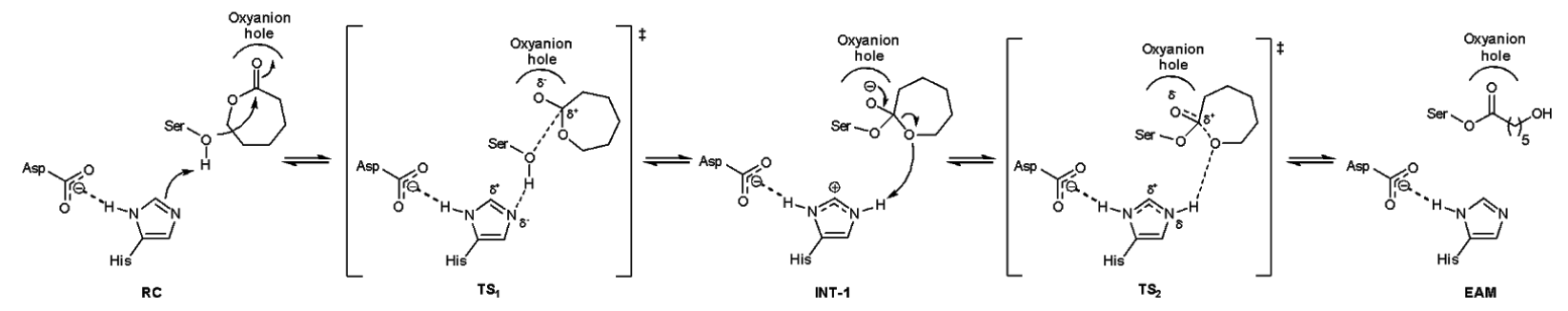

Fig. 2 General enzymatic mechanism for the acylation step of the ROP reaction.

Previously, we have determined the enzymatic catalytic mechanisms for the production of $\mathbf{P C} \mathbf{L}^{39,40}$ and PCL-PEG ${ }^{39,40}$ by WT-CalB and compared it to WT-AfEST and found important differences.

Here, we designed several mutants to make the first intermediate (INT-1) structure of AfEST more similar to the one of WT-CalB, to further stabilize the second transition state $\left(\mathbf{T S}_{\mathbf{2}}\right)$ structure and consequently, make the enzyme more active towards this product. We changed different regions in the enzyme, including the oxyanion hole residues, other residues that interact with the lactone ring and residues close to the histidine-aspartate pair. We found that for the best mutants we were able to decrease 
the overall free energy barriers for the rate-limiting step (Fig. 3). We predicted several mutants able to increase the formation of the polyesters that were later tested in-vitro.

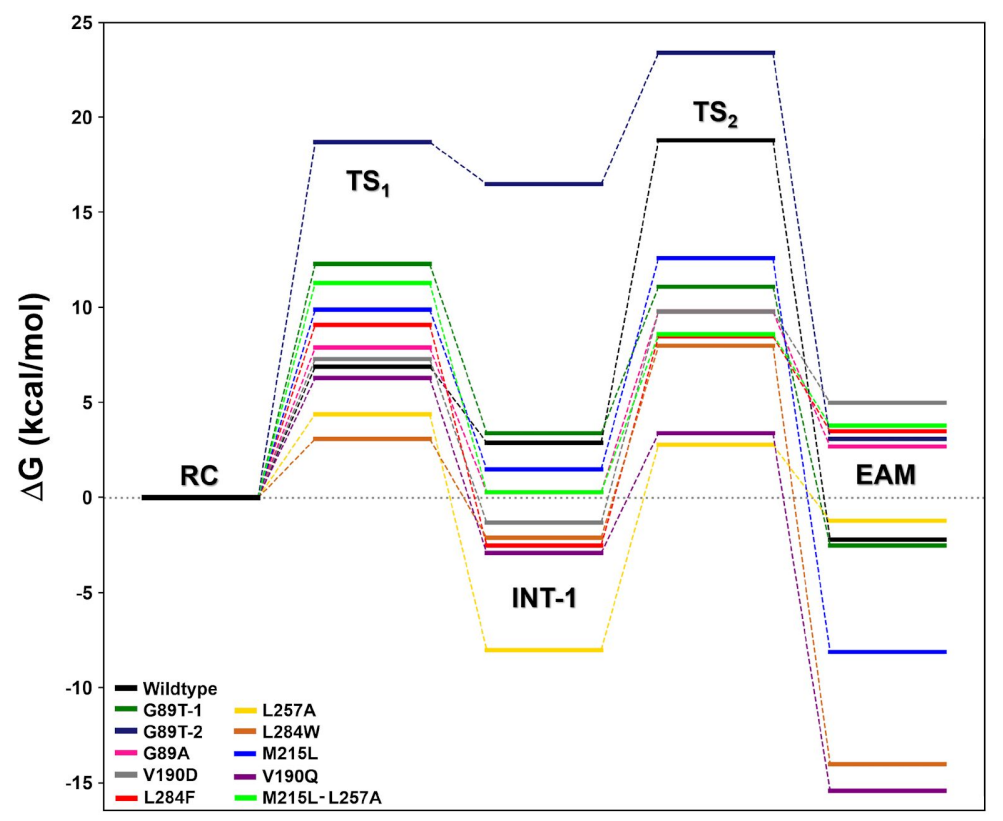

Fig. 3 Stationary points along the acylation step for the WT enzyme and mutants. Each line denotes the free energy for each mutant calculated with PM6/parm99SB and later corrected with the exchange-correlation functional B3LYP with Grimme D3 dispersion. ${ }^{41}$

\section{Mutation of the oxyanion hole residues}

The oxyanion hole regions of CalB and AfEST are significantly different. Whereas in CalB the hydrogen bond (HB) donors are the side-chain hydroxyl group of T40 and the backbone amides of T40 and Q106, in AfEST the HB donors are the backbone amides of G88, G89 and A161. The loop is also significantly larger in AfEST. In CalB, it spans 6 residues (from residue 38 to residue 43), wherein AfEST it is composed of 10 residues (86-95) (Fig. S1). When we superimpose the structures, we can observe that the loop residues closer to the nucleophilic serine are G39 and T40 in CalB, and G87, G88 and G89 in AfEST. T40 in CalB superimposes with G88/G89 in AfEST (Fig. S1 and S2). Accordingly, we have mutated G88 and G89 to threonine residues and tested their effect on $\mathbf{\varepsilon}-\mathbf{C l}$ binding and ring-opening. For 
G88T we observe that there is not enough space for the threonine side-chain to be facing the substrate. We observe a conformation where the threonine side-chain is oriented in the opposite direction (Fig. S3), but with a $\mathbf{T S}_{2}$ free energy barrier significantly higher than in the WT enzyme. Consequently, this mutation was discarded, and we focused instead on G89T. In this case, the new side-chain hydroxyl group of T89 is able to adopt two distinct conformations (G89T-1 and G89T-2, Fig. 4a and 4b, respectively): one where it is oriented towards the substrate negatively charged oxygen $\left(\mathrm{O}_{\text {oxy }}\right)$ facing the oxyanion hole (Fig. 4a), as T40 in CalB (Fig. S2b). For this conformation (1), the rate-limiting step is the first one, with a $\Delta \mathrm{G}^{\ddagger}$ of $12.3 \mathrm{kcal} / \mathrm{mol}$ (Fig. 3). In the RC structure (Fig. 4a), the distance between the serine hydroxyl hydrogen and the nitrogen atom of $\mathrm{H} 285$ is quite large (4.29 $\AA$ ), reflecting the fact that with this mutation, the active site needs to substantially reorganize to stabilize of the first transition state $\left(\mathbf{T S}_{\mathbf{1}}\right)$ structure. At the INT-1, the T89 side-chain and the remaining amide groups of the oxyanion hole region make HBs to the $\mathrm{O}_{\text {oxy }}$, while the $\mathrm{H} 285$ is making a weak $\mathrm{HB}$ to the lactone oxygen atom $\left(\mathrm{O}_{\text {lac }}\right)($ Fig. 2 and $4 \mathrm{~b})$. In the other G89T conformation (2), the side-chain hydroxyl is oriented in the opposite direction from the oxyanion hole region and it is making an $\mathrm{OH}-\pi$ interaction with the benzyl ring of the F218 side-chain. Therefore, the oxyanion hole region for this mutant is significantly different, since the negatively charged $\mathrm{O}_{\text {oxy }}$ makes a rather weak HB with A161 at both RC and INT-1 structures. Also, although H285 is closer to the $\mathrm{O}_{\text {lac }}$ than the serine oxygen $\left(\mathrm{O}_{\mathrm{Ser}}\right)$, the angles are far from ideal $\left(\beta=146.3^{\circ}, \alpha=143.1^{\circ}\right.$ and $\psi=128.6^{\circ}$, Fig. $4 \mathrm{~b}$ and $4 \mathrm{e}$ ) when comparing with the other conformation (1). As a consequence, the $\mathbf{T S}_{\mathbf{1}}$ and INT-1 structures from the second conformation are significantly higher in energy (INT-1 16.5 $\mathrm{kcal} / \mathrm{mol}$ above the $\mathbf{R C}$ ) and the overall free energy barrier of $23.4 \mathrm{kcal} / \mathrm{mol}$ is higher than in the WT enzyme (4.6 kcal/mol higher, Fig. 3, 4h and 4k). The presence of the new HB acceptor in a new enzyme scaffold is not necessarily better since it does not occupy the same relative position in the catalytic triad residues of CalB. Accordantly, in the results from the experimental validation for the G89T (Table 1), we observe some improvement for PCL synthesis, but no improvement for PCL-PEG synthesis. 


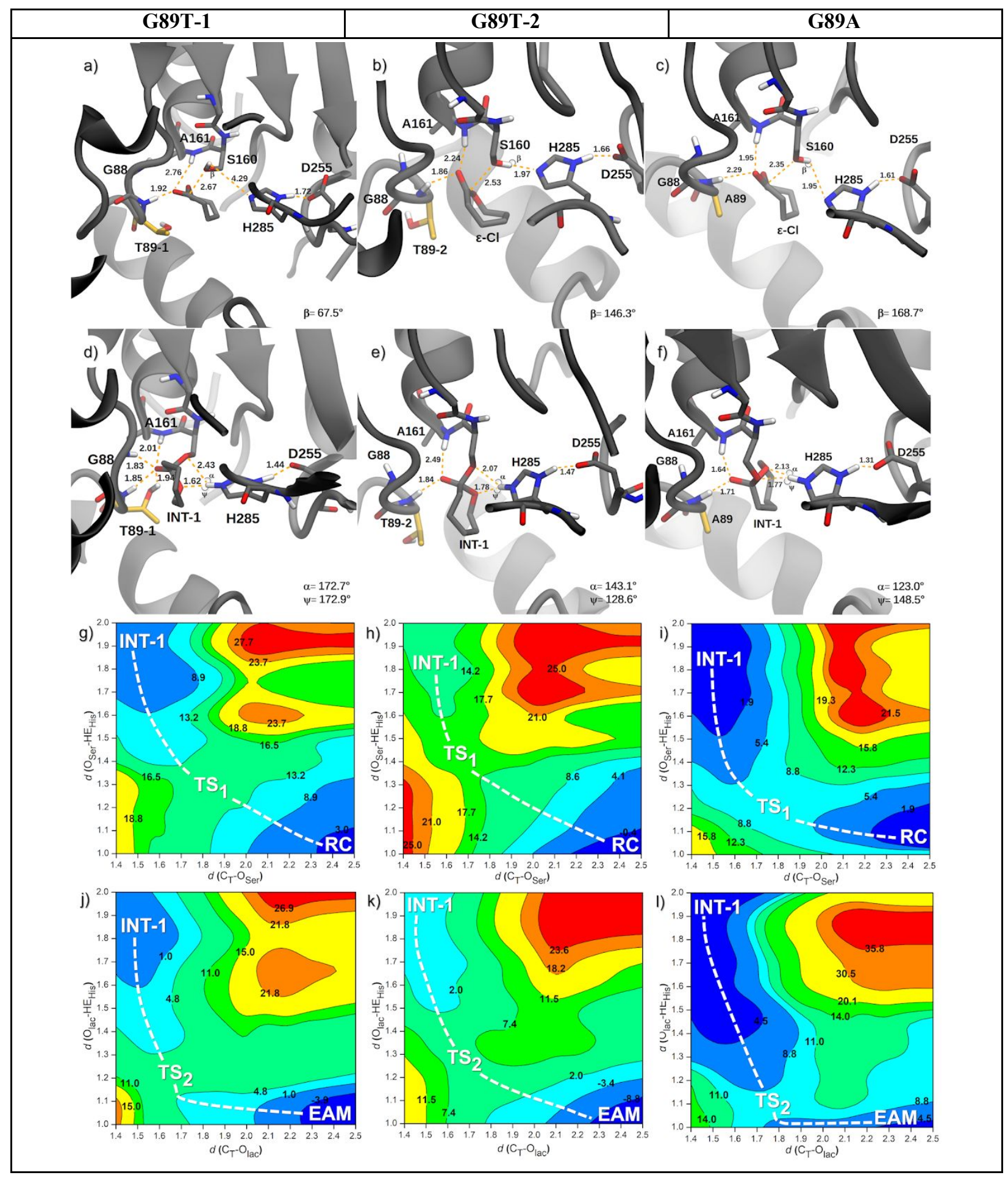


Fig. 4 Top) Reference structures for the AfEST mutants G89T-1, G89T-2 and G89A: RC with $\boldsymbol{\varepsilon}-\mathbf{C l}$ (a-c) and INT-1 (d-f). Bottom) Calculated 2D-PMFs for the first (g-i) and second (j-l) steps of G89T-1, G89T-2 and G89A. The distances are given in $\AA$ and the relative energy values in $\mathrm{kcal} / \mathrm{mol}$.

Since we noted that there is some improvement in placing in this position, the same residue that is present in CalB (for one of the conformations), we also tested other residues in this position, such as the G89A mutation (Fig. 4c), where we are substituting a highly flexible glycine with a residue with the small methyl side-chain. In this case, we also get a significant change in the conformation of the oxyanion loop. The change in position of the oxyanion loop is relayed to the $\mathrm{N}$-terminal $\alpha$-helix and the protein loop with the catalytic histidine (Fig. S4). Consequently, the distance between the $\mathrm{H} 285 \mathrm{HE}$ atom and $\mathrm{O}_{\text {Ser }}$ is improved at the $\mathbf{R C}$ structure and, at the INT-1, the distance towards $\mathrm{O}_{\text {lac }}$ is now $2.13 \AA$, which is also an improvement in relation to the WT enzyme (Fig. 4c and 4f, Table 1).

\section{Mutations in residues that interact with the lactone-ring}

The residues that line the lactone ring binding-site were also tested. The mutation V190Q, which occupies the same relative position of CalB-Q157, decreases the overall barrier to $11.5 \mathrm{kcal} / \mathrm{mol}$ (Fig. 3). The amide group of Q190 makes an HB with S219 (average distance of $2.51 \pm 0.40 \AA$ ), and the carbonyl group stays oriented towards the substrate, moving the $\mathrm{O}_{\text {lac }}$ away in the opposite direction (Fig. 5a). In the INT-1 structure, the H285 HE hydrogen is substantially closer to $\mathrm{O}_{\text {lac }}$, than to $\mathrm{O}_{\text {Ser }}$ (Fig. 5d). The $\mathbf{T S}_{1}$ has a free energy barrier of $11.5 \mathrm{kcal} / \mathrm{mol}$ and $\mathbf{T S} \mathbf{S}_{2} 8.8 \mathrm{kcal} / \mathrm{mol}$, making $\mathbf{T S}_{1}$ the rate-limiting step for this mutation (Fig. 3, 5g and 5j). When the same residue is mutated to a negatively charged aspartate residue (V190D), the aspartate carboxylate is oriented towards the backbone amide groups of residues V191 and N192 instead of the substrate. In the RC structure, the $\mathrm{O}_{\text {Ser }}$ is close to the carbonyl carbon of the substrate that is going to be attacked and the hydroxyl hydrogen is close to the $\mathrm{H} 285$ nitrogen atom (Fig $5 \mathrm{~b}$ ). TS $_{1}$ $\Delta \mathrm{G}^{\ddagger}$ is $7.3 \mathrm{kcal} / \mathrm{mol}$ (Fig. 3 and $5 \mathrm{~h}$ ). In the INT-1 structure, the $\mathrm{H} 285 \mathrm{HE}$ hydrogen is closer to the $\mathrm{O}_{\text {Ser }}$ 
than the $\mathrm{O}_{\text {lac }}$ and the barrier towards the $\mathbf{T S}_{2}$ amounts to $11.1 \mathrm{kcal} / \mathrm{mol}$ (Fig. 3, 5e and 5k). The overall barriers are similar in the two cases $(11.5$ and $11.1 \mathrm{kcal} / \mathrm{mol})$.

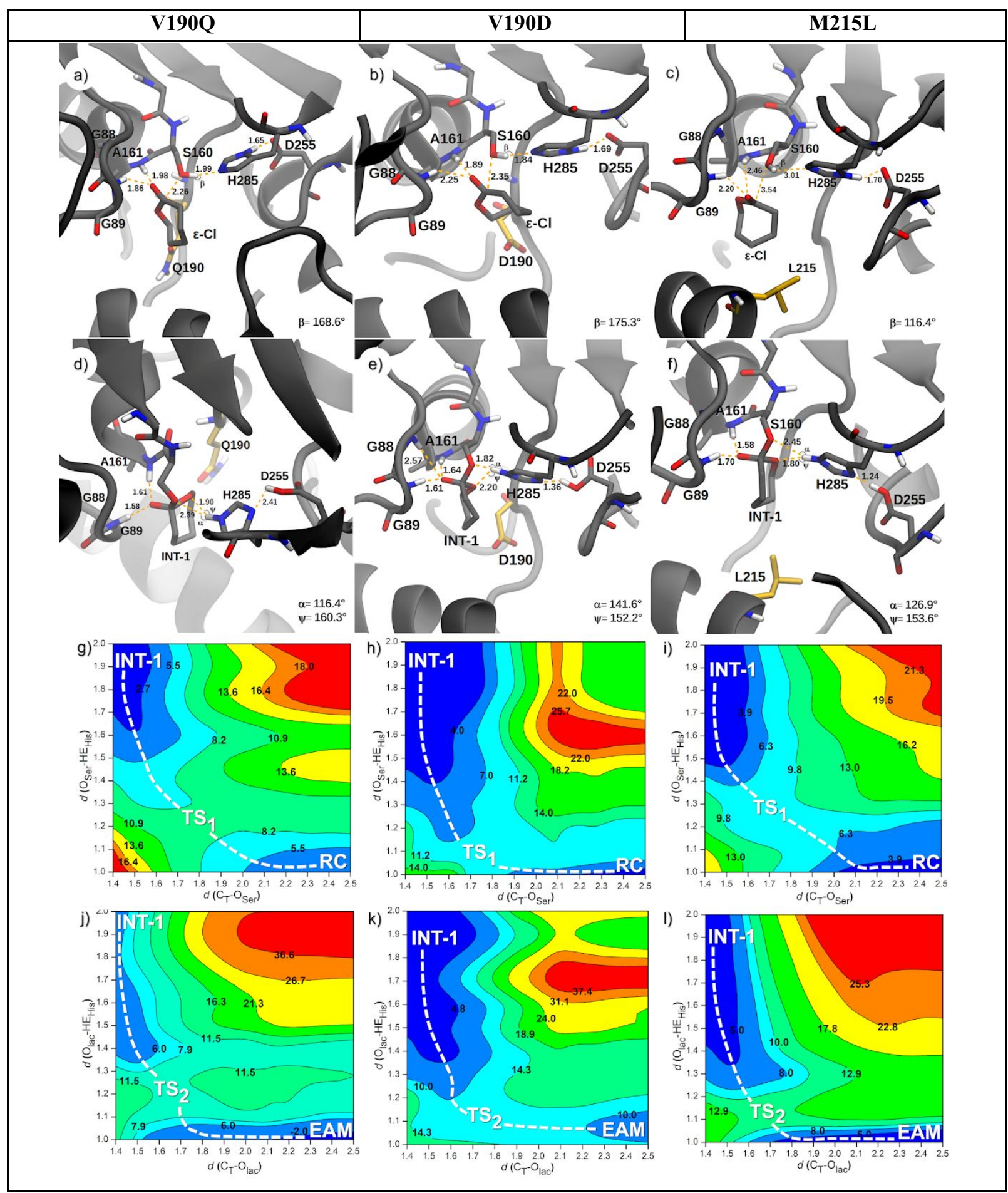


Fig. 5 Top) Reference structures for AfEST mutants V190Q, V190D and M215L: RC with $\mathbf{\varepsilon - C l ~ ( a - c ) ~ a n d ~}$ INT-1 (d-f). Bottom) Calculated 2D-PMFs for the first (g-i) and second (j-l) steps of V190Q, V190D and M215L. The distances are given in $\AA$ and the relative energy values in $\mathrm{kcal} / \mathrm{mol}$.

When M215 is mutated to a leucine (M215L) the shorter isobutyl side-chain creates more space in the binding pocket, allowing the substrate $\boldsymbol{\varepsilon}-\mathbf{C l}$ to bind in two different conformations (RC-1 and RC-2, Fig. $5 \mathrm{c}$ and S5, respectively). In the lowest energy structure, the substrate is close to the nucleophilic serine, but the substrate ring is rotated towards V190 (instead of M215, L257 as in the WT) and the $\mathrm{O}_{\text {oxy }}$ is not oriented towards the oxyanion hole region. There is then a second $\mathbf{R C}$ after ring rotation (2, Fig. S5), which is $7.3 \mathrm{kcal} / \mathrm{mol}$ above RC-1. The overall barrier for RC-1 is $12.6 \mathrm{kcal} / \mathrm{mol}$ (Fig. 3, $5 \mathrm{i}$ and 51 ). Although the observed barrier is in fact lower than the WT, in this case the substrate is not able to make such strong interactions as in the WT enzyme. Accordantly, the observed product yield is similar to the WT for PCL at $70^{\circ} \mathrm{C}$ and PCL-PEG at $90^{\circ} \mathrm{C}$.

\section{Mutations in residues near the catalytic His-Asp pair}

Finally, we have mutated residues that are close to the catalytic His-Asp pair. In the L257A mutation, the positions of D255 and H285 residues change significantly, which is translated in a good position of the nucleophilic serine to transfer the hydroxyl hydrogen to the $\mathrm{H} 285$ nitrogen atom and perform the nucleophilic attack. However, this mutation also affects $\boldsymbol{\varepsilon}-\mathbf{C l}$ binding (the interaction with L257 is now absent, Fig. S6). At the INT-1, the H285 is equidistant from $\mathrm{O}_{\text {lac }}$ and $\mathrm{O}_{\text {Ser }}(1.94$ and $1.95 \AA$, respectively, Fig. 6d) and the overall $\Delta \mathrm{G}^{*}$ is $10.8 \mathrm{kcal} / \mathrm{mol}$ (Fig. 3, $6 \mathrm{~g}$ and $6 \mathrm{j}$ ). 


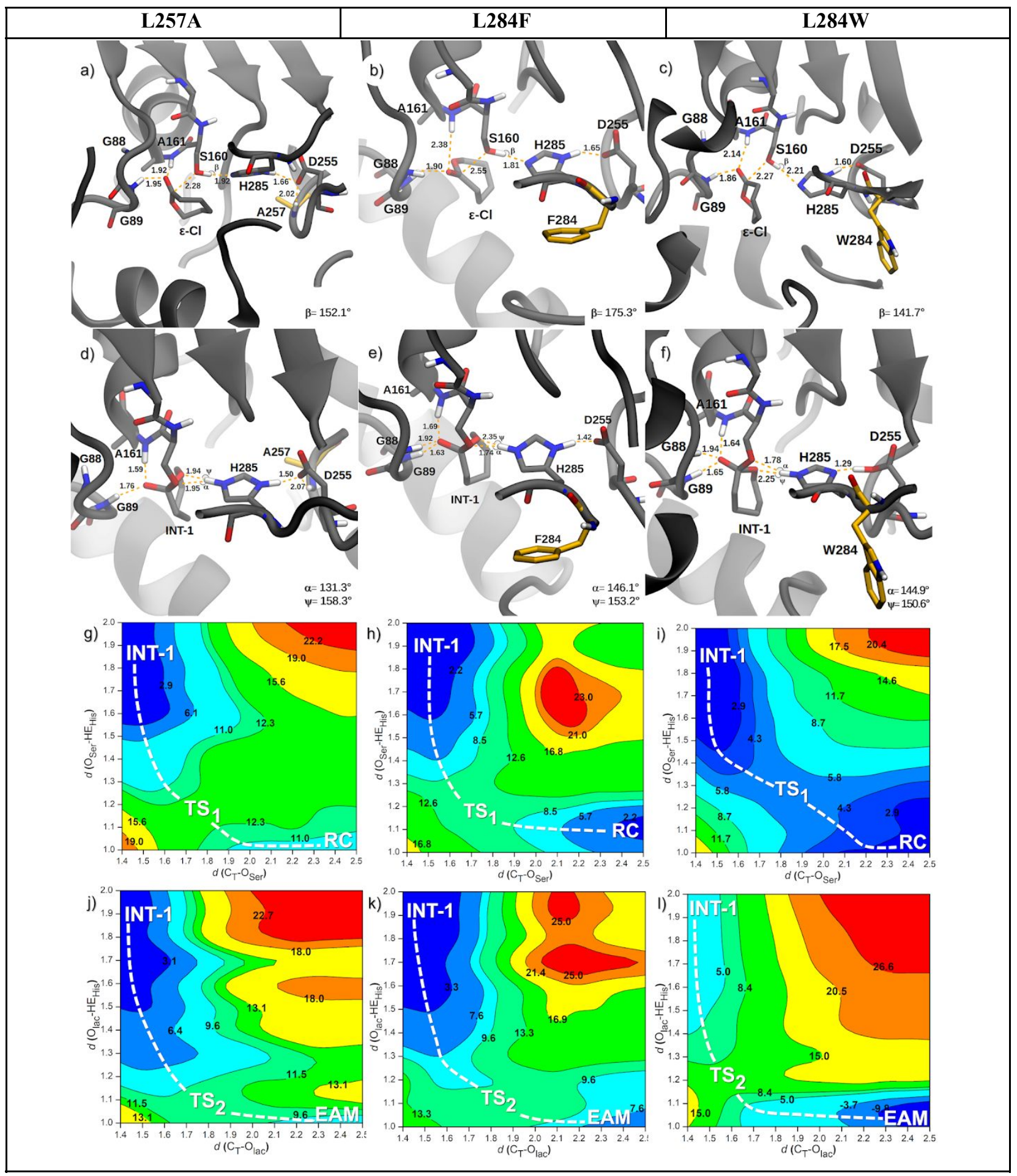


Fig. 6 Top) Reference structures for AfEST mutants L257A, L284F and L284W: RC with $\boldsymbol{\varepsilon}$-Cl (a-c) and INT-1 (d-f). Bottom) Calculated 2D-PMFs for the first (g-i) and second (j-1) steps of L257A, L284F and L284W. The distances are given in $\AA$ and the relative energy values in $\mathrm{kcal} / \mathrm{mol}$.

In the L284F and L284W mutations we see the same trend as before. The His-Asp pair moves and this leads to a better orientation of the protein dipoles for stabilization of INT-1 and to a similar or worst stabilization of $\mathbf{T S}_{\mathbf{2}}$ (Fig. 6h and 6k). The rate-limiting free energy barriers change to 11.0 and 10.8 $\mathrm{kcal} / \mathrm{mol}$, respectively (Figs. 6i and 61), which are significantly lower than in the WT enzyme (Fig. 3).

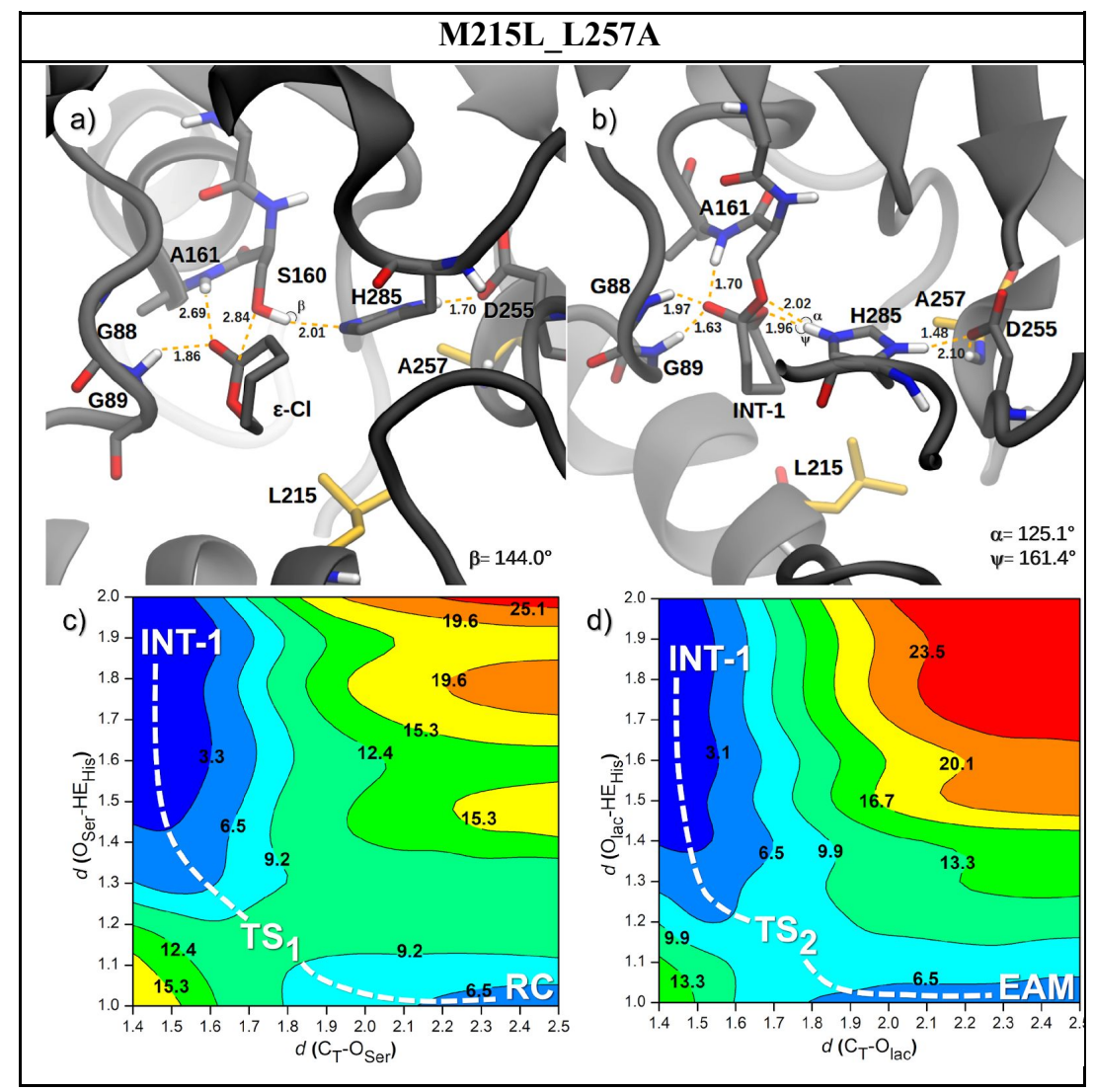

Fig. 7 Top) Reference structures of AfEST mutant active site M215L-L257A: RC with $\mathbf{\varepsilon - C l}(\mathbf{a})$ and INT-1 (b). Bottom) Calculated 2D-PMFs for the first (c) and second (d) steps of M215L-L257A. The distances are given in $\AA$ and the relative energy values in $\mathrm{kcal} / \mathrm{mol}$. 
Finally, in the double mutant M215L-L257A, we are combining a mutation adjacent to the catalytic aspartate with another, closer to the substrate. At the $\mathbf{R C}$, we observe a new position of the substrate that differs from both single mutants, where the substrate is closer to 192 and Y188, and above the nucleophilic serine (Fig. 7a and S6). The catalytic serine is still able to make an HB with the histidine. At the INT-1, we can see that the $\mathrm{H} 285$ is almost equidistant of $\mathrm{O}_{\text {lac }}$ and $\mathrm{O}_{\text {Ser }}(0.06 \AA$ difference, Fig. $7 \mathrm{~b})$. The $\Delta \mathrm{G}^{*}$ for this double mutant is $8.3 \mathrm{kcal} / \mathrm{mol}$ (Fig. 3, 7c and $7 \mathrm{~d}$ ).

\section{Reactions and products characterization}

In order to verify our computational predictions, we have expressed the WT enzymes and the characterized mutants. We have performed the synthesis of PCL and PCL-PEG at two different temperatures and characterized the obtained products by ATR FTIR. The selected temperature range was based in previous studies were higher monomer conversions were observed between $70-90{ }^{\circ} \mathrm{C}$, but products $\mathrm{M}_{\mathrm{n}}$ were higher at $70{ }^{\circ} \mathrm{C} .^{25,42}$

To check if the WT enzymes were active, we measured the remaining $\mathbf{\varepsilon}-\mathbf{C l}$ by GC (Table S1), which showed that AfEST enabled higher substrate conversion. Nevertheless, the remaining $\boldsymbol{\varepsilon}$-Cl might just indicate the formation of 6-hydroxycaproic acid. ${ }^{23} \mathrm{~A}$ better indication of polymer formation is based on products assessment, including the isolation yields, which are summarized in Table 1.

Table 1 Product yields (in \%) for PCL and PCL-PEG synthesis by the WT-AfEST and its mutants.

\begin{tabular}{ccccc}
\hline \multirow{2}{*}{ Mutation } & \multicolumn{2}{c}{ PCL } & \multicolumn{2}{c}{ PCL-PEG } \\
\cline { 2 - 5 } & $\mathbf{7 0}^{\mathbf{0}} \mathbf{C}$ & $\mathbf{9 0}^{\mathbf{0}} \mathbf{C}$ & $\mathbf{7 0}^{\mathbf{0}} \mathbf{C}$ & $\mathbf{9 0}^{\mathbf{0}} \mathbf{C}$ \\
\hline WT-AfEST & 9 & 12 & 9 & 44 \\
\hline G89T & 45 & 34 & 2 & 39 \\
\hline G89A & 32 & 47 & 26 & 56 \\
\hline V190Q & 30 & 53 & 16 & 47 \\
\hline V190D & 25 & 59 & 29 & 50 \\
\hline L257A & 29 & 48 & 27 & 55 \\
\hline L284F & 40 & 55 & 34 & 57 \\
\hline L284W & 34 & 55 & 70 & 66 \\
\hline
\end{tabular}




\begin{tabular}{ccccc}
\hline M215L-L257A & 60 & 42 & 9 & 28 \\
\hline WT-CalB & 0 & 9 & 0 & 8 \\
\hline
\end{tabular}

The AfEST-mediated ROP polymerizations gave rise to the typical white solid products with isolation yields varying between 2-70 \% for PCL-PEG copolymer. For PCL, isolation yields in the range of 9-60 $\%$ were obtained at $70{ }^{\circ} \mathrm{C}$ and in the range of $12-59 \%$ at $90{ }^{\circ} \mathrm{C}$.

For the mutants, we can relate the differences in product yields at the different temperatures with structural changes in enzyme loop containing the catalytic aspartate (D255, residues 253 to 257). For example, in the double mutant M215L-L257A, the product yield decreases 1.43 -fold for PCL at $90{ }^{\circ} \mathrm{C}$ when compared to the yield at $70{ }^{\circ} \mathrm{C}$. In this case, we are disrupting a Van der Waals (VdW) interaction between M215 and L257 (Fig. S6). In opposition, in the single mutant M215L, L215 is still able to interact with L257 and we observe an improvement in yields between the two temperatures. Importantly, the reactions carried out with the AfEST mutants provided in general a more efficient route to prepare PCL homopolymer and PCL-PEG copolymer, than simply using the WT or even compared to WT-CalB. For example, when comparing the PCL-PEG polymerization reaction carried out at $70{ }^{\circ} \mathrm{C}$ using WT-AfEST and L257A mutant, the yield increased from 12 to $49 \%$. Another important observation was that PCL-PEG was typically isolated in higher yields than in the case of PCL, independently of the mutant used.

Finally, the unambiguous confirmation of polyester formations was obtained from FTIR analysis.

Through the main FTIR spectroscopic features observed for all dried samples, notably (Fig. S7): two main bands near 2942 and $2964 \mathrm{~cm}^{-1}$ and a small shoulder at $c a .2880 \mathrm{~cm}^{-1}$, arising from the antisymmetric and symmetric stretching of C-H bond of methylene groups, characteristic of both PEG and PCL moieties; one very intense and sharp vibrational band near $1719 \mathrm{~cm}^{-1}$, attributed to the carbonyl stretching mode $(\mathrm{C}=\mathrm{O})$ of an ester moiety, characteristic of the PCL moiety; a band at $1469 \mathrm{~cm}^{-1}$, attributed to the $\mathrm{C}-\mathrm{H}$ bending vibration of PEG moiety; and another two high-intensity bands at 1237 and $1173 \mathrm{~cm}^{-1}$ attributed to the asymmetric and symmetric C-O-C stretching mode, also from an ester group, characteristic of PCL 
units. $^{43}$ Additionally, a broadband centered at around $3450 \mathrm{~cm}^{-1}$, arising from the terminal hydroxyl groups is also observed, which is consistent with the attainment of relatively low molecular weight polymers. Nevertheless, the relative intensity of this band compared with, for example, those at 2940 and $2963 \mathrm{~cm}^{-1}$, clearly decreases for those polymers obtained in higher yields and compared with the WT-CalB (e.g. L257A versus WT-CalB), thus, indicating higher molecular weights. All these attributions are in accordance with literature values for similar polymers and also with the polymers obtained with WT enzymes. ${ }^{43,44,45}$ These characterizations confirmed the success of the new AfEST-mutant mediated polymer synthesis, especially regarding the WT-AfEST and WT-CalB enzymes (Fig. S2). Moreover, the main spectroscopic features of the polymers enzymatically synthesized, confirmed the predominant aliphatic nature with ester linkages, typical of PCL-PEG copolymers. Further studies on those polymers obtained in higher amounts, can shed more light on their properties.

\section{Discussion}

Here, we have reengineered the thermophilic AfEST carboxylesterase for more efficient synthesis of the aliphatic polyesters (PCL and PCL-PEG), which are interesting biomaterials. Our reengineering approach was based on the detailed mechanistic characterization of the eROP for PCL and PCL-PEG copolymers synthesis by CalB lipase and AfEST carboxylesterase enzymes. As discussed before, ${ }^{39}$ the WT-CalB and WT-AfEST enzymes share many common aspects but are significantly different. The very different oxyanion hole loop and disposition of the catalytic triad really precludes making simple substitutions. Nevertheless, some aspects could be mimicked, such as decreasing the oxyanion loop flexibility, changing the polarity of the active site, or changing the relative position of the His-Asp pair. By analyzing the results, a common pattern emerges: if the oxygen atom that is directly involved in the reaction is able to form a hydrogen bond with the histidine in the minima, then the barrier will be lower. This purely reflects that, for these mutants, there is a better pre-organization of the active site to stabilize the corresponding transition state for this substrate. Because this is a multistep mechanism, involving the same catalytic machinery (the histidine acting as a base in the first step and as an acid in the second), we 
also observe a compromise for re-organization. This means that having a particular disposition that favors a smaller barrier when going from the reactants to the $\mathbf{T S}_{1}$, can have a detrimental effect on the second step, where the active site rearrangement is necessary for the histidine to stabilize instead the leaving group $\left(\mathrm{O}_{\text {lac }}\right)$. If at the INT-1 structure, the histidine interacts strongly with the $\mathrm{O}_{\text {Ser }}$, then the reaction tends to go backwards toward the reagents. For example, for the WT-AfEST INT-1, the active site is better organized to stabilize the backwards reaction to the RC, instead of the forward one to the EAM. For G89T, and particularly G89T-2, the disposition is such that, no productive hydrogen bond is formed between the $\mathrm{H} 285$ and $\mathrm{O}_{\text {Ser }}$ and consequently there is a much higher free energy barrier at $\mathbf{T S}_{\mathbf{1}}$ (from the RC to INT-1). The best fold improvement for PCL is for the double mutant (M215L-L257A) at $70{ }^{\circ} \mathrm{C}$ for PCL (60\% product yield, Table 1) and L284W at $70{ }^{\circ} \mathrm{C}$ for PCL-PEG (70 \% product yield, Table 1$)$. In both cases, the distances and angles at the optimized structures of the RCs are consistent with weak hydrogen bonds $\left(2.2 \AA, 141.7^{\circ}\right.$ for L284W and $2.0 \AA, 144.0^{\circ}$ for M215L-L257A). At the INT-1, the measured values to the $\mathrm{O}_{\text {Ser }}$ and $\mathrm{O}_{\text {lac }}$ are similar and consistent with a moderate to weak hydrogen bonds (Fig. 6f and 7b).

By changing the active site of AfEST in such a way to optimize the active site arrangement and by achieving the best compromise possible between $\mathbf{T S} \mathbf{S}_{\mathbf{1}}$ and $\mathbf{T} \mathbf{S}_{2}$ stabilization, we were able to design mutants that were confirmed to produce polymers with higher yields than the WT enzyme. The role in nature of this enzyme is far from synthetizing polyesters. Here we have improved it to do just that.

\section{Methods}

\section{Initial Setup}

The structure of the WT and mutants complexed with the first tetrahedral intermediate (INT-1) (Fig. 8) were modeled from the AfEST crystal structure (1JJI, ${ }^{33} 2.20 \AA$ resolution, homodimer) and the 
protonation states assigned with MolProbity. ${ }^{46}$ Before any procedure, the sulfonic inhibitor present in the crystal structure was removed to generate a suitable initial structure for the subsequent computational analysis. The INT-1 molecule was geometry optimized in Gaussian09 ${ }^{47}$ using B3LYP ${ }^{48}$ with the 6-31G(d) basis set and a Polarizable Continuum Model (PCM $)^{49}$ solvent description. The atomic partial charges were calculated from the optimized structure resorting to the Restrained Electrostatic Potential (RESP) ${ }^{50}$ method from the HF/6-31G(d,p) single-point energy calculations. Amino-acid substitutions were made resorting to rotamer's libraries. ${ }^{51}$ All complexes were minimized and subjected to Molecular Dynamics (MD) simulations prior to the determination of the reaction profiles.

\section{Molecular Dynamics}

Molecular Dynamics (MD) simulations of all complexes were performed using the Amber molecular dynamics program (AMBER18) $)^{52}$ with the parm99SB ${ }^{53}$ and $\mathrm{GAFF}^{54}$ force fields. The structures were placed within a pre-equilibrated octahedral box of toluene (as previously parameterized) ${ }^{55}$ with a distance between the surface of the protein to the box of $10.0 \AA .24 \mathrm{Na}^{+}$ions were added to make the entire system neutral.

The systems were subjected to two initial energy minimizations and 500 ps of equilibration in an $N V T$ ensemble using Langevin dynamics with small restraints on the protein of $10.0 \mathrm{kcal} / \mathrm{mol}$ to heat the systems. Production simulations of $5 \mathrm{~ns}$ were carried out at $353.15 \mathrm{~K}$ in the NPT ensemble using Langevin dynamics with a collision frequency of $1 \mathrm{ps}^{-1}$. Constant pressure periodic boundary conditions were imposed with an average pressure of $1 \mathrm{~atm}$. Isotropic position scaling was used to maintain pressure with a relaxation time of 2 ps. The time step was set to 2 fs. SHAKE constraints were applied to all bonds involving hydrogen atoms. ${ }^{56}$ The Particle Mesh Ewald (PME) method ${ }^{57}$ was used to calculate electrostatic interactions with a cut-off distance of 10.0 A. 


\section{Quantum Mechanics/Molecular Mechanics Calculations}

The Quantum Mechanics/Molecular Mechanics (QM/MM) calculations ${ }^{58,59}$ were performed using the internal semi-empirical hybrid QM/MM functionality implemented in AMBER18 ${ }^{52}$ with periodic boundary conditions. A MD reference structure of each complex was used as the initial structure for the QM/MM calculations. The PM6 semi-empirical method ${ }^{60,61}$ was employed to describe the QM region while the MM region was described by the Amber parm99SB force field. ${ }^{53}$ The reactions were conducted at $353.15 \mathrm{~K}$. Electrostatic embedding ${ }^{62}$ was employed and the boundary treated via the link atom approach. Long-range electrostatic interactions were described by an adapted implementation of the PME $\operatorname{method}^{57}$ for QM/MM. ${ }^{63}$

For the 1D and 2D-PMFs the same set of reaction coordinates was used (Fig. 8). They are: 1) the distance between the $\mathrm{H} 285$ proton $\mathrm{HE}$ and the $\mathrm{D} 159$ oxygen atom $(\theta)$ and 2) the distance between the $\mathrm{H} 285$ proton HE and the substrate oxygen atom $(\phi)$.

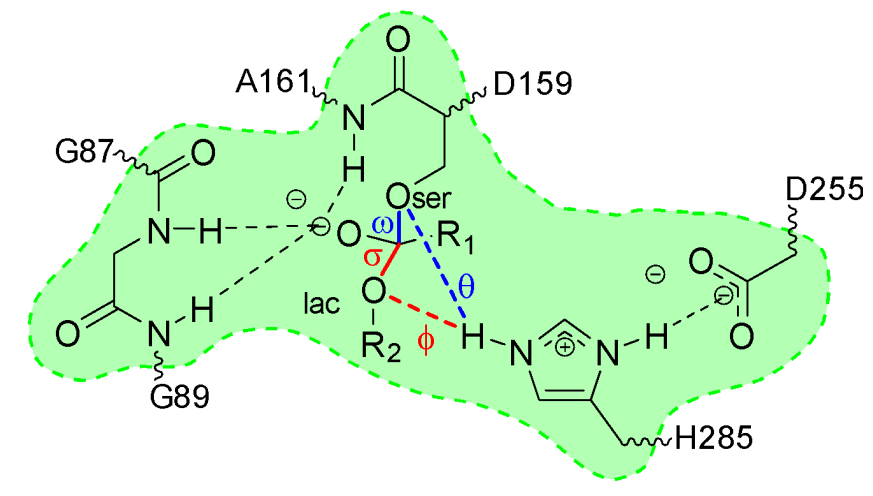

Fig. 8 Representation of the QM region and corresponding link atoms. INT-1 $\mathrm{R}_{1}, \mathrm{R}_{2}=\left(\mathrm{CH}_{2}\right)_{5}$.

In the 1D-PMF, one reaction coordinated was restrained in $0.1 \AA$ steps using the umbrella sampling method, except near the transition states were smaller steps of $0.02 \AA$ were employed. Then, and in accordance with our previous work, ${ }^{39}$ the structures from 1D profiles were used as starting points for the 2D-PMF scans. To keep the reaction coordinates at the requested distances and to ensure enough overlap between windows, an umbrella constraint force of $200 \mathrm{~kJ} \cdot \mathrm{mol}^{-1} \cdot \mathrm{A}^{-2}$ was used along the reaction path and 
incrementally increased to $1000 \mathrm{~kJ} \cdot \mathrm{mol}^{-1} \cdot \mathrm{A}^{-2}$ as the reaction coordinates deflect from the minimum energy path. For every window, a total of $15 \mathrm{ps}$ was simulated with a time step of $1 \mathrm{fs}$. The distances were scanned from 1.4 to $2.5 \AA$ ( $\omega$ and $\sigma)$ and from 1.0 to $2.0 \AA(\theta$ and $\phi)$ comprising a total of 132 simulations for each step and for each mutant. The minimum energy path was traced resorting to the MEPSA software version $1.4^{64}$ and the PMFs computed resorting to the Weighted Histogram Analysis Method (WHAM) with the Monte Carlo bootstrap error analysis. ${ }^{65,66}$ The average structures for the minima in the PMFs were retrieved and optimized with PM6/parm99SB and used to make all the figures.

\section{High-level Layer Corrections}

For the high-level (HL) layer corrections of the 2D-PMFs we resorted to the method described in detail in reference ${ }^{67}$ which is based on the work of Truhlar and co-workers. ${ }^{68,69}$ Multiple structures were retrieved from the 2D-PMFs and subjected to single-point calculations using the Gaussian09 program, ${ }^{47}$ first with the semi-empirical PM6 ${ }^{60,61}$ and then with B3LYP ${ }^{48}$ with Grimme D3 dispersion. ${ }^{41}$ The corrected energies term $(E)$ was interpolated from those structures employing the following equation:

$$
E=E_{P M 6 / M M}+S\left(\Delta E_{P M 6}^{B 3 L Y P}\right)
$$

Where the term $\triangle E_{P M 6}^{B 3 L Y P}$ corresponds to the difference between the free energies for the HL layer set calculated by B3LYP/6-31G(d,p) ${ }^{48}$ with Grimme D3 dispersion ${ }^{41}$ and PM6 ${ }^{60,61}$ (low level (LL) theory), while $S$ represents the cubic spline function of the difference between the HL and LL theory representing the QM region. All energies mentioned in the text are from the corrected 2D-PMFs with B3LYP/6-31G(d,p) and with Grimme D3 dispersion. ${ }^{41}$

\section{Plasmids Design and Protein Expression}

The genes for the WT enzymes and the mutants were synthetized and cloned in pET-24a $(+)$ expression vectors by GenScript. ${ }^{70}$

Plasmids were transformed into BL21 Escherichia coli (E. coli) competent cells and grown on antibiotic 
selection plates. Primary cultures were inoculated from agar plates and grown overnight at $37{ }^{\circ} \mathrm{C}$ and diluted 1:100 into $1 \mathrm{~L} \mathrm{LB}$ supplemented with $50 \mu \mathrm{g} / \mathrm{mL}$ kanamycin. Cultures were grown at $37^{\circ} \mathrm{C}$ until induction with $1 \mathrm{mM}$ IPTG and incubated at $25^{\circ} \mathrm{C}$ for $16 \mathrm{hr}$. Cells were harvested by centrifugation at $4000 \mathrm{rpm}$ for $0.5 \mathrm{hr}$ and resuspended in $0.1 \mathrm{M}$ phosphate buffer $\mathrm{pH}$ 7.4. CalB samples were split with half being prepared as freeze-dried whole cells (W/C). The remaining CalB samples were sonicated alongside AfEST samples to lyse cells. The cell free extract (CFE) was collected by centrifugation to remove unbroken cells and cellular debris and then freeze-dried to yield an off-white solid.

Enzyme expression was detected using a dot blot and all cultures showed detection of a His-tag indicating expression of the esterases and lipases (Fig. S8). Following cell lysis, $2 \mu \mathrm{L}$ cell free extract was spotted onto nitrocellulose membrane and allowed to air dry before being incubated at $25^{\circ} \mathrm{C}$ for $1 \mathrm{hr}$ in blocking solution with shaking (5\% milk powder in phosphate buffer saline (PBS)). After decanting the blocking solution, the membrane was washed 3 times for 1 min in PBS. Monoclonal Anti-polyHistidine-Peroxidase was diluted 1:10,000 in PBS and incubated for $1 \mathrm{hr}$ at $37^{\circ} \mathrm{C}$ with shaking. The antibody solution was decanted and the membrane washed 3 times for 5 min in PBS before addition of the development solution (6 mg diaminobenzidine in $10 \mathrm{~mL}$ PBS and $100 \mu \mathrm{L}$ hydrogen peroxide). The membrane was developed with shaking until brown coloration of blotted enzymes appeared and the solution was decanted, membrane washed with $\mathrm{MQH}_{2} \mathrm{O}$ and imaged.

\section{Reactions Set-up}

ROP reactions of $200 \mu \mathrm{L}$ of substrate $(\boldsymbol{\varepsilon}-\mathrm{Cl})$ in $600 \mu \mathrm{L}$ of toluene were carried out at $70{ }^{\circ} \mathrm{C}$ and $90{ }^{\circ} \mathrm{C}$ for $72 \mathrm{hr}$. The dried enzyme (cell free extracts or whole cells, Table S1) was added to each reaction medium to reach a concentration of $25 \mathrm{mg} / \mathrm{mL}$ In the case of the assays for PCL-PEG synthesis, $50 \mu \mathrm{L}$ of

PEG4000 were added as well. WT-AfEST and WT-CalB samples were analyzed by Gas

Chromatography (GC) to evaluate the remaining $\boldsymbol{\varepsilon}-\mathbf{C l}$. The GC analysis was carried out using an Agilent 7890B GC equipped with an Agilent HP-5 column (30 m x $0.32 \mathrm{~mm} \times 0.25 \mu \mathrm{m})$ and ran with a $160{ }^{\circ} \mathrm{C}$ 
isocratic oven method for 5 min. The injection was performed using a Gas flow inlet with a 25:1 split ratio at a constant pressure of $22 \mathrm{psi}$. The inlet and detector temperatures were $250^{\circ} \mathrm{C}$. Helium was used as carrier gas maintained at a flow rate of $25 \mathrm{~mL} / \mathrm{min}$. The air and hydrogen flow rates set to $450 \mathrm{~mL} / \mathrm{min}$ and $40 \mathrm{ml} / \mathrm{min}$, respectively.

\section{Polymers Characterization}

The newly synthesized PCL and PCL-PEG copolymers were extensively characterized by means of Attenuated total reflectance Fourier transform infrared (ATR FTIR) spectroscopy to assess their main structural features. Additionally, for comparison reasons, the copolymer synthesized using the WT-AfEST was also analyzed by ATR FTIR. ATR FTIR spectra of all polymers were obtained using a PARAGON 1000 FTIR spectrometer equipped with a single-horizontal Golden Gate ATR cell (Perkin-Elmer, MA, United States). The spectra were recorded after $128 \mathrm{scans}$, at a resolution of $4 \mathrm{~cm}^{-1}$, within the range of 500 to $4000 \mathrm{~cm}^{-1}$.

\section{Acknowledgements}

This work was financed by Portuguese national funds via FCT - Fundação para a Ciência e a Tecnologia, under project(s) MIT-Portugal (MIT-EXPL/ISF/0021/2017), the grant IF/01272/2015, within the scope of the projects CNC.IBILI UID/NEU/04539/2019 and CICECO - Aveiro Institute of Materials UIDB/50011/2020 \& UIDP/50011/2020, financed by national funds through the FCT - Fundação para a Ciência e a Tecnologia / MEC and when appropriate co-financed by FEDER under the PT2020 Partnership Agreement. This research is also sponsored by FEDER funds through the program COMPETE - Programa Operacional Factores de Competitividade - and by national funds through FCT under the project UID/EMS/00285/2020. The costs resulting from the FCT hiring of A.F.S. were funded by national funds (OE), through FCT - Fundação para a Ciência e a Tecnologia, I.P., in the scope of the framework contract foreseen in the numbers 4, 5 and 6 of the article 23 of the Decree-Law 57/2016 of 
August, changed by Law 57/2017 of 19 July. The authors also acknowledge the Coimbra Institute of Engineering (ISEC) for computing resources made available through the Minerva HPC.

\section{Author Information Notes}

Correspondence should be addressed to Alexandra T. P. Carvalho: atpcarvalho@uc.pt, www.atpcarvalho.com.

\section{Associated Content}

Supplementary information is available for this paper.

\section{References}

(1) Cameron, D. J. A.; Shaver, M. P. Aliphatic Polyester Polymer Stars: Synthesis, Properties and Applications in Biomedicine and Nanotechnology. Chem. Soc. Rev. 2011, 40 (3), 1761-1776. https://doi.org/10.1039/C0CS00091D.

(2) Hutanu, D.; Frishberg, M. D.; Guo, L.; Darie, C. C. Recent Applications of Polyethylene Glycols (PEGs) and PEG Derivatives. Mod. Chem. Appl. 2014, 2 (2), 1-6.

https://doi.org/10.4172/2329-6798.1000132.

(3) Grossen, P.; Witzigmann, D.; Sieber, S.; Huwyler, J. PEG-PCL-Based Nanomedicines: A Biodegradable Drug Delivery System and Its Application. J. Control. Release 2017, 260, 46-60. https://doi.org/10.1016/j.jconrel.2017.05.028.

(4) Jérôme, C.; Lecomte, P. Recent Advances in the Synthesis of Aliphatic Polyesters by Ring-Opening Polymerization. Adv. 2008, 60 (9), 1056-1076. https://doi.org/10.1016/j.addr.2008.02.008.

(5) Zhang, J.; Shi, H.; Wu, D.; Xing, Z.; Zhang, A.; Yang, Y.; Li, Q. Recent Developments in Lipase-Catalyzed Synthesis of Polymeric Materials. Process. Biochem. 2014, 49 (5), 797-806. https://doi.org/10.1016/j.procbio.2014.02.006. 
(6) Kadokawa, J.; Kobayashi, S. Polymer Synthesis by Enzymatic Catalysis. Curr. Opin. Chem. Biol. 2010, 14 (2), 145-153. https://doi.org/10.1016/j.cbpa.2009.11.020.

(7) Albertsson, A.-C.; Srivastava, R. K. Recent Developments in Enzyme-Catalyzed Ring-Opening Polymerization. Adv. 2008, 60 (9), 1077-1093. https://doi.org/10.1016/j.addr.2008.02.007.

(8) Yang, Y.; Yu, Y.; Zhang, Y.; Liu, C.; Shi, W.; Li, Q. Lipase/Esterase-Catalyzed Ring-Opening Polymerization: A Green Polyester Synthesis Technique. Process. Biochem. 2011, 46 (10), 1900-1908. https://doi.org/10.1016/j.procbio.2011.07.016.

(9) Shoda, S.; Uyama, H.; Kadokawa, J.; Kimura, S.; Kobayashi, S. Enzymes as Green Catalysts for Precision Macromolecular Synthesis. Chem. Rev. 2016, 116 (4), 2307-2413. https://doi.org/10.1021/acs.chemrev.5b00472.

(10) Zhao, H. Enzymatic Ring-Opening Polymerization (ROP) of Polylactones: Roles of Non-Aqueous Solvents. J. Chem. Technol. Biotechnol. 2018, 93 (1), 9-19. https://doi.org/10.1002/jctb.5444.

(11) Uyama, H.; Kobayashi, S. Enzymatic Ring-Opening Polymerization of Lactones Catalyzed by Lipase. Chem. Lett. 1993, 22 (7), 1149-1150. https://doi.org/10.1246/cl.1993.1149.

(12) Kobayashi, S. Enzymatic Ring-Opening Polymerization and Polycondensation for the Green Synthesis of Polyesters. Polym. Adv. Technol. 2015, 26 (7), 677-686. https://doi.org/10.1002/pat.3564.

(13) Abedalwafa, M.; Wang, F.; Wang, L.; Li, C. Biodegradable poly-epsilon-caprolactone (PCL) for tissue engineering applications: a review. Rev. Adv. Mater. Sci. 2013, 34, 123-140.

(14) Huang, Y.; Li, L.; Li, G. An Enzyme-Catalysed Access to Amphiphilic Triblock Copolymer of PCL-b-PEG-b-PCL: Synthesis, Characterization and Self-Assembly Properties. Des. Monomers Polym. 2015, 18 (8), 799-806. https://doi.org/10.1080/15685551.2015.1078113.

(15) He, F.; Li, S.; Vert, M.; Zhuo, R. Enzyme-Catalyzed Polymerization and Degradation of Copolymers Prepared from €-Caprolactone and Poly(Ethylene Glycol). Polymer 2003, 44 (18), 5145-5151. https://doi.org/10.1016/S0032-3861(03)00562-7. 
(16) Poojari, Y.; Beemat, J. S.; Clarson, S. J. Enzymatic Synthesis of Poly(ع-Caprolactone): Thermal Properties, Recovery, and Reuse of Lipase B from Candida Antarctica Immobilized on Macroporous Acrylic Resin Particles. Polym. Bull. 2013, 70 (5), 1543-1552.

https://doi.org/10.1007/s00289-013-0916-1.

(17) Polloni, A. E.; Veneral, J. G.; Rebelatto, E. A.; de Oliveira, D.; Oliveira, J. V.; Araújo, P. H. H.; Sayer, C. Enzymatic Ring Opening Polymerization of $\omega$-Pentadecalactone Using Supercritical Carbon Dioxide. The Journal of Supercrit. Fluids 2017, 119, 221-228.

https://doi.org/10.1016/j.supflu.2016.09.019.

(18) Zhao, H.; Nathaniel, G. A.; Merenini, P. C. Enzymatic Ring-Opening Polymerization (ROP) of Lactides and Lactone in Ionic Liquids and Organic Solvents: Digging the Controlling Factors. RSC Adv. 2017, 7 (77), 48639-48648. https://doi.org/10.1039/C7RA09038B.

(19) Pellis, A.; Comerford, J. W.; Weinberger, S.; Guebitz, G. M.; Clark, J. H.; Farmer, T. J. Enzymatic Synthesis of Lignin Derivable Pyridine Based Polyesters for the Substitution of Petroleum Derived Plastics. Nat. Commun. 2019, 10 (1), 1762. https://doi.org/10.1038/s41467-019-09817-3.

(20) Poojari, Y.; Clarson, S. J. Thermal Stability of Candida Antarctica Lipase B Immobilized on Macroporous Acrylic Resin Particles in Organic Media. Biocatal. Agric.Biotechnol. 2013, 2 (1), 7-11. https://doi.org/10.1016/j.bcab.2012.10.002.

(21) Champagne, E.; Strandman, S.; Zhu, X.-X. Recent Developments and Optimization of Lipase-Catalyzed Lactone Formation and Ring-Opening Polymerization. Macromol. 2016, 37, 1986-2004. https://doi.org/10.1002/marc.201600494.

(22) Yang, J.; Liu, Y.; Liang, X.; Yang, Y.; Li, Q. Enantio-, Regio-, and Chemoselective Lipase-Catalyzed Polymer Synthesis. Macromol. Biosc. 2018, 18 (7), 1800131. https://doi.org/10.1002/mabi.201800131.

(23) Montanier, C. Y.; Chabot, N.; Emond, S.; Guieysse, D.; Remaud-Siméon, M.; Peruch, F.; André, I. Engineering of Candida Antarctica Lipase B for Poly(ع-Caprolactone) Synthesis. Eur. 2017, 95, 809-819. https://doi.org/10.1016/j.eurpolymj.2017.07.029. 
(24) Vieille, C.; Zeikus, G. J. Hyperthermophilic Enzymes: Sources, Uses, and Molecular Mechanisms for Thermostability. Microbiol. Mol. Biol. Rev. 2001, 65 (1), 1-43.

https://doi.org/10.1128/MMBR.65.1.1-43.2001.

(25) Ma, J.; Li, Q.; Song, B.; Liu, D.; Zheng, B.; Zhang, Z.; Feng, Y. Ring-Opening Polymerization of $\varepsilon$-Caprolactone Catalyzed by a Novel Thermophilic Esterase from the Archaeon Archaeoglobus Fulgidus. J. Mol. Catal. B Enzym. 2009, 56 (2), 151-157.

https://doi.org/10.1016/j.molcatb.2008.03.012.

(26) Li, G.; Li, Q. Thermophilic Esterase from the Archaeon Archaeoglobus Fulgidus Physically Immobilized on Hydrophobic Macroporous Resin: A Novel Biocatalyst for Polyester Synthesis. Biotechnol. Bioprocess Eng. 2011, 16 (6), 1201-1207. https://doi.org/10.1007/s12257-011-0260-y. Ren, H.; Xing, Z.; Yang, J.; Jiang, W.; Zhang, G.; Tang, J.; Li, Q. Construction of an Immobilized Thermophilic Esterase on Epoxy Support for Poly( $\varepsilon$-Caprolactone) Synthesis. Molecules 2016, 21 (6). https://doi.org/10.3390/molecules21060796.

(28) Bezborodov, A. M.; Zagustina, N. A. Lipases in Catalytic Reactions of Organic Chemistry. Appl. Biochem. Microbiol. 2014, 50 (4), 313-337. https://doi.org/10.1134/S0003683814040024.

(29) Simón, L.; Goodman, J. M. Enzyme Catalysis by Hydrogen Bonds: The Balance between Transition State Binding and Substrate Binding in Oxyanion Holes. J. Org. Chem. 2010, 75 (6), 1831-1840. https://doi.org/10.1021/jo901503d.

(30) Douka, A.; Vouyiouka, S.; Papaspyridi, L.-M.; Papaspyrides, C. A Review on Enzymatic Polymerization to Produce Polycondensation Polymers: The Case of Aliphatic Polyesters, Polyamides and Polyesteramides. Prog. Polym. Sci. 2017, 79. https://doi.org/10.1016/j.progpolymsci.2017.10.001.

(31) Brady, L.; Brzozowski, A. M.; Derewenda, Z. S.; Dodson, E.; Dodson, G.; Tolley, S.; Turkenburg, J. P.; Christiansen, L.; Huge-Jensen, B.; Norskov, L.; Thim, L.; Menge, U. A Serine Protease Triad Forms the Catalytic Centre of a Triacylglycerol Lipase. Nature 1990, 343 (6260), 767. https://doi.org/10.1038/343767a0. 
Protonation and the Mechanism of Interfacial Activation. J. Lipid Res. 2015, 56 (12), 2348-2358. https://doi.org/10.1194/jlr.M063388.

$$
\text { De Simone, G.; Menchise, V.; Manco, G.; Mandrich, L.; Sorrentino, N.; Lang, D.; Rossi, M.; }
$$

Pedone, C. The Crystal Structure of a Hyper-Thermophilic Carboxylesterase from the Archaeon Archaeoglobus Fulgidus11Edited by R. Huber. J. Mol. Biol. 2001, 314 (3), 507-518. https://doi.org/10.1006/jmbi.2001.5152.

(34) Uppenberg, J.; Hansen, M. T.; Patkar, S.; Jones, T. A. The Sequence, Crystal Structure Determination and Refinement of Two Crystal Forms of Lipase B from Candida Antarctica. Structure 1994, 2 (4), 293-308. https://doi.org/10.1016/S0969-2126(00)00031-9.

(35) Publishers, B. S. Protein \& Peptide Letters, 6th ed.; Bentham Science Publishers, 1997; Vol. 4.

(36) Lutz, S.; Iamurri, S. M. Protein Engineering: Past, Present, and Future. Methods Mol. Biol. 2018, 1685, 1-12. https://doi.org/10.1007/978-1-4939-7366-8_1.

(37) Wang, Y.; Li, B.; Han, W.; Yang, G.; Zhang, Z.; Feng, Y. Redesigning the Active Site of a Carboxyl Esterase from the Archaeon Archaeoglobus Fulgidus to Improve Sensitivity to Organophosphorus Compounds. Process Biochem. 2012, 47 (12), 2219-2226. https://doi.org/10.1016/j.procbio.2012.08.021.

(38) Ma, F.; Chung, M. T.; Yao, Y.; Nidetz, R.; Lee, L. M.; Liu, A. P.; Feng, Y.; Kurabayashi, K.; Yang, G.-Y. Efficient Molecular Evolution to Generate Enantioselective Enzymes Using a Dual-Channel Microfluidic Droplet Screening Platform. Nat. Commun 2018, 9 (1), 1-8. https://doi.org/10.1038/s41467-018-03492-6.

(39) Figueiredo, P.; Almeida, B.; Dourado, D. F. A. R.; Sousa, A.; Silvestre, A.; Pires Carvalho, A. T. Enzymatic Synthesis of Polyesters: A QM/MM Study. ChemCatChem 2020, 12, 4845. https://doi.org/10.1002/cctc.202000780. 
(40) Figueiredo, P.; Almeida, B. C.; Carvalho, A. T. P. Enzymatic Polymerization of PCL-PEG

Co-Polymers for Biomedical Applications. Front. Mol. Biosci. 2019, 6, 109.

https://doi.org/10.3389/fmolb.2019.00109.

(41) Grimme, S.; Antony, J.; Ehrlich, S.; Krieg, H. A Consistent and Accurate Ab Initio

Parametrization of Density Functional Dispersion Correction (DFT-D) for the 94 Elements H-Pu. $J$.

Chem. Phys. 2010, 132 (15), 154104. https://doi.org/10.1063/1.3382344.

(42) Cao, H.; Han, H.; Li, G.; Yang, J.; Zhang, L.; Yang, Y.; Fang, X.; Li, Q. Biocatalytic Synthesis of Poly $(\delta$-Valerolactone) Using a Thermophilic Esterase from Archaeoglobus Fulgidus as Catalyst. Int.

J. Mol. Sci. 2012, 13 (10), 12232-12241. https://doi.org/10.3390/ijms131012232.

(43) Gökalp, N.; Ulker, C.; Guvenilir, Y. Synthesis of Polycaprolactone via Ring Opening

Polymerization Catalyzed by Candida Antarctica Lipase B Immobilized onto an Amorphous Silica

Support. J. Polym. Mater. 2016, 33 (1), 87-100.

(44) Huang, Y.; Li, L.; Li, G. An Enzyme-Catalysed Access to Amphiphilic Triblock Copolymer of

PCL-b-PEG-b-PCL: Synthesis, Characterization and Self-Assembly Properties. Desi. Monomers

Polym. 2015, 18 (8), 799-806. https://doi.org/10.1080/15685551.2015.1078113.

(45) Sousa, A. F.; Coelho, J. F. J.; Silvestre, A. J. D. Renewable-Based Poly((Ether)Ester)s from

2,5-Furandicarboxylic Acid. Polymer 2016, 98, 129-135.

https://doi.org/10.1016/j.polymer.2016.06.015.

(46) Chen, V. B.; Arendall, W. B.; Headd, J. J.; Keedy, D. A.; Immormino, R. M.; Kapral, G. J.;

Murray, L. W.; Richardson, J. S.; Richardson, D. C. MolProbity: All-Atom Structure Validation for Macromolecular Crystallography. Acta Crystallogr. D. Biol. Crystallogr. 2010, 66 (Pt 1), 12-21. https://doi.org/10.1107/S0907444909042073.

(47) Frisch, M.; Trucks, G.; Schlegel, H.; Scuseria, G.; Robb, M.; Cheeseman, J.; Scalmani, G.;

Barone, V.; Mennucci, B.; Petersson, G.; Nakatsuji, H.; Caricato, M.; Li, X.; Hratchian, H.;

Izmaylov, A.; Bloino, J.; Zheng, G.; Sonnenberg, J.; Hada, M.; Ehara, M.; Toyota, K.; Fukuda, R.;

Hasegawa, J.; Ishida, M.; Nakajima, T.; Honda, Y.; Kitao, O.; Nakai, H.; Vreven, T.; Montgomery, 
J.; Peralta, J.; Ogliaro, F.; Bearpark, M.; Heyd, J.; Brothers, E.; Kudin, K.; Staroverov, V.;

Kobayashi, R.; Normand, J.; Raghavachari, K.; Rendell, A.; Burant, J.; Iyengar, S.; Tomasi, J.; Cossi, M.; Rega, N.; Millam, J.; Klene, M.; Knox, J.; Cross, J.; Bakken, V.; Adamo, C.; Jaramillo, J.;

Gomperts, R.; Stratmann, R.; Yazyev, O.; Austin, A.; Cammi, R.; Pomelli, C.; Ochterski, J.; Martin, R.; Morokuma, K.; Zakrzewski, V.; Voth, G.; Salvador, P.; Dannenberg, J.; Dapprich, S.; Daniels, A.; Farkas; Foresman, J.; Ortiz, J.; Cioslowski, J.; Fox, D. Gaussian 09, Revision B.01. Gaussian 09, Revision B.01, Gaussian, Inc., Wallingford CT 2009.

(48) Ashvar, C. S.; Devlin, F. J.; Bak, K. L.; Taylor, P. R.; Stephens, P. J. Ab Initio Calculation of Vibrational Absorption and Circular Dichroism Spectra: 6,8-Dioxabicyclo[3.2.1]Octane. J. Phys. Chem. 1996, 100 (22), 9262-9270. https://doi.org/10.1021/jp953738p.

(49) Tomasi, J.; Mennucci, B.; Cammi, R. Quantum Mechanical Continuum Solvation Models. Chem.

Rev. 2005, 105 (8), 2999-3094. https://doi.org/10.1021/cr9904009.

(50) Bayly, C. I.; Cieplak, P.; Cornell, W.; Kollman, P. A. A Well-Behaved Electrostatic Potential

Based Method Using Charge Restraints for Deriving Atomic Charges: The RESP Model. J. Phys.

Chem. 1993, 97 (40), 10269-10280. https://doi.org/10.1021/j100142a004.

(51) Pettersen, E. F.; Goddard, T. D.; Huang, C. C.; Couch, G. S.; Greenblatt, D. M.; Meng, E. C.;

Ferrin, T. E. UCSF Chimera--a Visualization System for Exploratory Research and Analysis. $J$

Comput Chem 2004, 25 (13), 1605-1612. https://doi.org/10.1002/jcc.20084.

(52) Salomon-Ferrer, R.; Case, D. A.; Walker, R. C. An Overview of the Amber Biomolecular Simulation Package: Amber Biomolecular Simulation Package. Wiley Interdiscip. Rev. Comput. Mol.

Sci. 2013, 3 (2), 198-210. https://doi.org/10.1002/wcms.1121.

(53) Hornak, V.; Abel, R.; Okur, A.; Strockbine, B.; Roitberg, A.; Simmerling, C. Comparison of Multiple AMBER Force Fields and Development of Improved Protein Backbone Parameters.

Proteins 2006, 65 (3), 712-725. https://doi.org/10.1002/prot.21123. 
(54) Wang, J.; Wolf, R. M.; Caldwell, J. W.; Kollman, P. A.; Case, D. A. Development and Testing of a General Amber Force Field. J. Comput. Chem. 2004, 25 (9), 1157-1174. https://doi.org/10.1002/jcc.20035.

(55) Trodler, P.; Pleiss, J. Modeling Structure and Flexibility of Candida Antarctica Lipase B in Organic Solvents. BMC Struct. Biol. 2008, 8 (1), 9. https://doi.org/10.1186/1472-6807-8-9.

(56) Ryckaert, J.-P.; Ciccotti, G.; Berendsen, H. J. C. Numerical Integration of the Cartesian Equations of Motion of a System with Constraints: Molecular Dynamics of n-Alkanes. J. Comput. Phys. 1977, 23 (3), 327-341. https://doi.org/10.1016/0021-9991(77)90098-5.

(57) Darden, T.; York, D.; Pedersen, L. Particle Mesh Ewald: An N·log(N) Method for Ewald Sums in Large Systems. J. Chem. Phys. 1998, 98, 10089. https://doi.org/10.1063/1.464397.

(58) Warshel, A.; Levitt, M. Theoretical Studies of Enzymic Reactions: Dielectric, Electrostatic and Steric Stabilization of the Carbonium Ion in the Reaction of Lysozyme. J. Mol. Biol. 1976, 103 (2), 227-249. https://doi.org/10.1016/0022-2836(76)90311-9.

(59) Carvalho, A. T. P.; Barrozo, A.; Doron, D.; Kilshtain, A. V.; Major, D. T.; Kamerlin, S. C. L. Challenges in Computational Studies of Enzyme Structure, Function and Dynamics. J. Mol. Graph. Model. 2014, 54, 62-79. https://doi.org/10.1016/j.jmgm.2014.09.003.

(60) Stewart, J. J. P. Optimization of Parameters for Semiempirical Methods V: Modification of NDDO Approximations and Application to 70 Elements. J. Mol. Model. 2007, 13 (12), 1173-1213. https://doi.org/10.1007/s00894-007-0233-4.

(61) Jindal, G.; Warshel, A. Exploring the Dependence of QM/MM Calculations of Enzyme Catalysis on the Size of the QM Region. J. Phys. Chem. B 2016, 120 (37), 9913-9921. https://doi.org/10.1021/acs.jpcb.6b07203.

(62) Bakowies, D.; Thiel, W. Hybrid Models for Combined Quantum Mechanical and Molecular Mechanical Approaches. J. Phys. Chem. 1996, 100 (25), 10580-10594. https://doi.org/10.1021/jp9536514. 
(63) Nam, K.; Gao, J.; York, D. M. An Efficient Linear-Scaling Ewald Method for Long-Range Electrostatic Interactions in Combined QM/MM Calculations. J. Chem. Theory Comput. 2005, 1 (1), 2-13. https://doi.org/10.1021/ct049941i.

(64) I, M.-A.; J, S.; Ji, M.-M.; J, M.; P, G.-P. MEPSA: Minimum Energy Pathway Analysis for Energy Landscapes. Bioinformatics 2015, 31 (23), 3853-3855.

https://doi.org/10.1093/bioinformatics/btv453.

(65) Kumar, S.; Rosenberg, J. M.; Bouzida, D.; Swendsen, R. H.; Kollman, P. A. THE Weighted Histogram Analysis Method for Free-Energy Calculations on Biomolecules. I. The Method. $J$. Comput. Chem. 1992, 13 (8), 1011-1021. https://doi.org/10.1002/jcc.540130812.

(66) Grossfield, A. An Implementation of WHAM: The Weighted Histogram Analysis Method Version 2.0.9. 2018, 18. http://membrane.urmc.rochester.edu/wordpress/?page_id=126 (2018).

(67) Ruiz-Pernía, J. J.; Silla, E.; Tuñón, I.; Martí, S.; Moliner, V. Hybrid QM/MM Potentials of Mean Force with Interpolated Corrections. J. Phys. Chem. B 2004, 108 (24), 8427-8433. https://doi.org/10.1021/jp049633g.

(68) Nguyen, K. A.; Rossi, I.; Truhlar, D. G. A Dual-Level Shepard Interpolation Method for Generating Potential Energy Surfaces for Dynamics Calculations. J. Chem Phys. 1995, 103 (13), 5522-5530. https://doi.org/10.1063/1.470536.

(69) Chuang, Y.-Y.; Corchado, J. C.; Truhlar, D. G. Mapped Interpolation Scheme for Single-Point Energy Corrections in Reaction Rate Calculations and a Critical Evaluation of Dual-Level Reaction Path Dynamics Methods. J. Phys. Chem. A 1999, 103 (8), 1140-1149. https://doi.org/10.1021/jp9842493.

(70) GenScript - Make Research Easy - The leader in molecular cloning and gene synthesis, peptide synthesis, protein and antibody engineering. https://www.genscript.com/ (accessed Jul 21, 2020). 
